OUR ASTRONOMICAL COLUMN.

Astronomical Occurrences for June:-

June I. 5h. om. Mercury at greatest elongation W. of the Sun $\left(24^{\circ} 30^{\prime}\right.$ W. $)$.

6. $\quad 15 \mathrm{~h} .0 \mathrm{~m}$. Mars at greatest heliocentric latitude $\mathrm{S}$.

7. $17 \mathrm{~b} .6 \mathrm{~m}$. Jupiter in conjunction with the Moon. (Jupiter $\mathrm{I}^{\circ} \mathrm{O}^{\prime} \mathrm{N}$.).

I4. I4h. $16 \mathrm{~m}$. Uranus in conjunction with the Moon. (Uranus $4^{\circ} 35^{\prime} \mathrm{N}$.).

20. I2h. $44 \mathrm{~m}$. Mars in conjunction with the Moon. (Mars $0^{\circ} \mathrm{I} 2^{\prime} \mathrm{N}$.)

22. Ih. $35 \mathrm{~m}$. Sun enters Sign of Cancer. Solstice.

22. 22h. $38 \mathrm{~m}$. Saturn in conjunction with the Moon. (Saturn $3^{\circ} 3^{\prime}$ S.).

25. 9h. I4m. Mercury in conjunction with the Moon. (Mercury $3^{\circ} 32^{\prime} \mathrm{S}$.)

27. $2 \mathrm{~h} .38 \mathrm{~m}$. Neptune in conjunction with the Moon. (Neptune $5^{\circ} 28^{\prime} \mathrm{S}$.)

29. 5h. $8 \mathrm{~m}$. Venus in conjunction with the Moon. (Venus $3^{\circ} 40^{\prime} \mathrm{S}$.).

29. I 3 h. Om. Mercury in perihelion.

The Tail of Halley's Comet on May 20, 1910.-No. 4496 of the Astronomische Nachrichten contains further notes on the question of the direction of the tail of Halley's comet on the evening of May 20, 1910. Irof. Eginitis returns to the discussion, with M. Antoniadi, concerning the appearance of a tail directed towards the sun, and suggests that the latter has failed to recognise the exceptional position of the tail, with regard to the earth and sun, at the time, and also its curvature; such conditions would account for the phenomena observed at Athens about which Prof. Eginitis has no doubt and M. Antoniadi contends were impossible.

The Spectrum of the Ring Nebula in Lyra.-Some interesting spectra of the Ring Nebula are published by Mr. Keivin Burns in No. 193 of the Lick Observatory Bulletins. The photographs were taken with a slitless spectroscope attached to the Crossley reflector, in order to determine the spectral type of the central star. Stained and unstained plates were employed, and, in passing, it is interesting to note that a "Cramer Crown" plate stained twenty-one days previously was 50 per cent. faster in the red than a newly stained plate from the same box. The length of the spectrum is only $3.3 \mathrm{~mm}$. between $\lambda \lambda 6560$ and 3730 , and the width of the image of the Ring is I.6 mm. in declination.

A comparison of adjacent stellar spectra with the spectrum of the central star showed that while between $\lambda \lambda 6600$ and 5800 , the latter was only as bright as a 14.2 mag. star of type A or F; at $\lambda 3300$ it was as bright as an F-type star of magnitude 12.4 . In fact, 'the spectrum of the central star is relatively stronger in the ultraviolet than that of the bluest of the many Orion-type stars which have been photographed with the same instrument; yet there is not the great difference between the visual and photographic magnitudes of this star that there is generally thought to be. Mr. Burns states that, if isolated, both the central star and the other star within the Ring would be easy objects for moderately large telescopes; he finds their visual magnitudes, by photographic methods, to be 14.1 and 14.7 , while their photographic magnitudes are $I_{3} .2$ and 14.5 respectively. The similarity of the spectrum of the central star to the spectra of central stars, or condensations, in other nebulæ removes any doubt as to its connection with the nebula.

The following radiations were found in the spectrum of the nebula itself :- $\lambda \lambda$ 3450, 3730, 387o, 3970 ( $\mathrm{H \epsilon})$, 4100 $(\mathrm{H} \delta), 4340(\mathrm{H} \gamma), 4690,4860(\mathrm{H} \beta), 4960-5010$ (chief nebula line), $5880\left(\mathrm{D}_{3}\right)$, and $6560(\mathrm{H} \alpha)$. Of these, the radiation at $\lambda 3730$ is by far the strongest, on the ordinary plate, and is followed by the chief nebula line; the hydrogen lines are relatively faint. The sizes of the rings due to $\lambda 3730$ and the hydrogen lines appear to be the same, while those due to the nebula lines $\lambda \lambda 3^{8} 80$ and 500 appear to be smaller. The monochromatic images of the ring show far more detail than a composite image, a fact which suggests that they differ in detail.

Proper Motions of Stars between $+75^{\circ}$ and $+80^{\circ}$ Declination.-By the comparison of the positions deterNO. 2 I69, VOL. 86$]$ mined at the Kasan Observatory with those given in twenty-two earlier catalogues, Prof. Dubiago has determined the proper motions of some 730 stars, and publishes them in No. 4496 of the Astronomische Nachrichten. All these stars occur in the Kasan A.G. zone between declinations $+75^{\circ}$ and $+80^{\circ}$, and the complete results are to appear in No. xv. of the Publications of the Kasan Observatory.

The Gyro-compass.-A brief description of the gyrocompass, which was exhibited at a recent meeting of the Royal Astronomical Society, appears in the May number of The Observatory (No. 435, p. 190). This compass is quite independent of the earth's magnetism, and may therefore be employed in many positions where an ordinary magnetic compass would be useless. It was, in fact, primarily designed for use in polar research, but now proves to be quite unsuitable; it is, however, trustworthy between latitudes $70^{\circ} \mathrm{N}$. and S., and is being adopted by several Governments for use in their navies.

The rotating disc is floated on mercury, so that it is free to move in two directions, and the rotation of the earth causes the axis to set itself due north and south. The axis is geared up to an indicator, so that the needle always points $\mathrm{N}$. and $\mathrm{S}$. when the gyro is running. The rotation of the disc is produced by an ingenious electric motor of which the disc forms part, and the inherent tendency to prolonged oscillation is overcome by a most ingenious system of damping by currents of air, the application of the blasts depending upon the amplitude of the oscillation at the moment.

A fuller description of the instrument is given by $\mathrm{Mr}$. G. K. B. Elphinstone in a book, "The Anschütz GyroCompass," published by Hugh Rees, Ltd.

ANCIENT OBSERVATORIES in INDIA.-An illustrated description of the five astronomical observatories erected at the beginning of the eighteenth century by Saway Jay Singh, the Maharaja of Ambhery in Rajputana, is one of the interesting papers in the May number of L'Astronomie. M. Ducret, who describes the equipments, states that the observatories were situated at Benares, Muttra, Delhi, Ujjain, and Jaipur, but with the exception of the last named they are in a sad state of ruin. A photograph of the Jaipur Observatory shows huge masonry erections by which the altitudes and azimuths of the celestial bodies could be determined. The installation shows that in $1718-34$, when the observatory was erected, the study of astronomy of position was well advanced in India.

\section{THE BRITISH SOLAR ECLIPSE} EXPEDITION.

$\mathrm{A}^{\mathrm{T}}$ the moment of writing we are fifty-five days out from home, and are steaming along steadily in H.M.S. Encounter towards the island of Vavau, which we hope to reach on Sunday evening next (April 2). Since leaving Sydney, on March 25, we have experienced a N.E. or head wind all the time, which has somewhat reduced our speed. To-day we are in lat. $25^{\circ} 20 \cdot 5^{\prime}$ and long. $174^{\circ}$ E., i.e. we are well to the north-east of Norfolk Island and to the south of Hunter or Fearn Island.

When boarding the ss. Otway at Tilbury on February 3 , I was the sole representative of the Solar Physics Observatory's expedition on board, for Father Cortie and Brother McKeon, who joined the ship at the same time, represent the party sent out by the Joint Eclipse Committee. It was not long before I discovered that many cases containing self-recording instruments, books, photographic materials, lantern-slides, \&c., for use on the voyage, were not placed in my cabin, and it was only at Port Said that I finally heard by cable that they were all neatly stowed away in No. 2 hatch with hundreds of tons of cargo above them, and therefore inaccessible until Sydney was reached. Fortunately, I had my $5 \times 4$ Kodak with me, and supplies of films were easily obtained at Marseilles, Naples and Colombo en route.

On the whole, the weather was cold for the time of year on the way out to Australia, and it was only in the doldrums that a high temperature and moisture-laden 
atmosphere were felt. I had intended to keep running three self-recording instruments, lent me by $\mathrm{Dr}$. W. N. Shaw, to record pressure, temperature, and the hydrometric state of the atmosphere on the way out and home; but, alas! these were in No. 2 hatch.

We reached Marseilles on February 9, and Mr. F. K. McClean, a volunteer for my party, joined the ship, having travelled overland from London. Unfortunately, we passed Messina at $3 \mathrm{a} . \mathrm{m}$. in the morning, so that the scene of the great earthquake could not be distinguished.

Solar halos were visible daily, and these corroborated the low temperatures we were experiencing. On February ${ }_{15}$ Port Said was sighted; it was a beautiful morning, but the air distinctly chilly. The same evening we entered the canal, and took only sixteen hours to get through. In the Gulf of Suez, even with a following wind, it was not hot; in fact, low temperatures were the chief features of the voyage. At Aden my notes state :"It has been exceptionally cool the whole journey, and especially through the Red Sea."

In the Indian Ocean the temperature began to rise, and the thermometer in my deck cabin, with an electric fan running, registered usually $78^{\circ}-82^{\circ}$ F. at about $\mathrm{Ix} \cdot 3 \mathrm{O}$ p.m. Colombo was reached on February 25, and although it was somewhat warm on shore, it was nothing to what it was in December, 1897 , when I was there on the way out to India for the eclipse of 1898 . On the evening of February' 26 we had a fine display of lightning. The colour of the flashes was a distinct violet, and each flash, or rather the great majority of them, appeared to quiver, i.e. did not seem to be instantaneous, and gave the impression that several flashes passed down the same path in the air. The flashes were, however, too distant to photograph; otherwise I would have recorded their multiple nature by photographing them with a moving camera. The phosphorescence on the water was brilliant that evening (and my cabin temperature $83^{\circ} \mathrm{F}$.). I have never been farther south than Colombo before, and so I had been looking forward with considerable interest to reaching the doldrums. I wished to observe and photograph the beautiful cloudscapes which are special to that tegion.

Monday, February 27, I labelled my cloud day. There were small but superb cumuli sailing over the sky slowly all day. Each cumulus was practically a nimbus, and rain was falling in dense sheets from most of them. The under surface of each cumulus was very flat, and their bottoms seemed to be about 4000-5000 feet high. As we were roughly in latitude $7^{\circ}$, the sun at midday was very high-nearly overhead. Thus the lower portions of the clouds were in deep shadow, and, looking towards the horizon, tier upon tier of their lower portions, due to perspective, made an impressive sight. This day ended with one of the most majestic sunsets I have ever seen. The sun, sinking behind these distant cumuli, rendered them of varied colours. Some were picked out in inkyblack with golden edges, while others were tinged with a ruddy hue, with purple for their main mass. Just above the sun, but tremendously high up in the upper reaches of our atmosphere, was a beautiful delicate mass of cirrocumulus in the form of waves. These exhibited all the colours of the rainbow, and were brilliant in the extreme. NO. 2 I69, VOL. 86$]$
A powerful pair of binoculars showed both their structure and colour. Beautiful golden rays also shot up from the sun, making the scene one of perfect beauty. The sight of these rays at sunset are alluded to by sailors as " the sun setting his back stays." After the sun had set, all the clouds became an inky-violet colour, and took all shapes, from French poodles to whales or 4.7 guns. This wonderful sunset was followed next day by an even more perfect sunrise. The sea exhibited that oily look so well depicted by Somerscales-and long rollers were sluggishly passing by making the Otway pitch a little. Even the bow way of the Otway refused in this oily sea to break, but sped silently away from the ship's side. The horizon at the east, with the distant yet unilluminated cumuli, brought to one's mind spectroheliograph photographs of the sun's limb with the prominences around it, the cloudforms representing the latter. Gradually the most beautiful dawn began to appear, and the sequence of events during the sunrise seemed to be exactly the reverse of the sunset the night before. In this case the "front stays of the sun "formed a conspicuous feature.

The evenings now were very warm and humid, and my

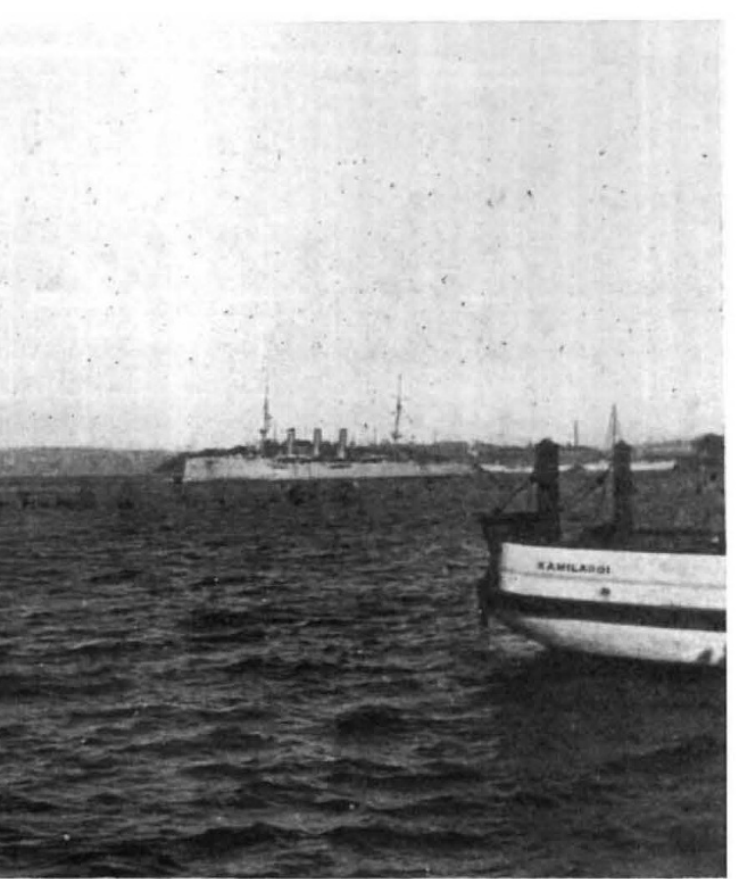

cabin temperatures, at about II.30 p.m., varied from $82^{\circ}$ to $85^{\circ} \mathrm{F}$., even with the electric fan running.

The approach to Australia is not very inspiring, for the coast at Fremantle is very low-lying, both to the north and south. It was here that I first experienced the great kindness of Mr. H. A. Hunt, the Commonwealth meteorologist, during my brief visit to Australia. Knowing that the ship would put in at Fremantle, he arranged for the meteorologist of the Perth district, Mr. Kerr Lewis, to meet me and show me round Perth. But I left the ship to catch the steamer for Perth instead of the train, so we missed each other, and I did not see him until I returned to the Otway again in the afternoon. Mr. McClean and I and a Mr. E. C. Anderson, whom I have commandeered as a volunteer observer for our expedition to Vavau, went off and visited the Perth Observatory. It was there we learnt that $\mathrm{Mr}$. Cooke, the director, was away in Melbourne on the Boundary Commission, and we gathered some information about the Australian eclipse party to Vavau also. Mr. Kerr Lewis, the chief assistant at the observatory, very kindly showed us over the observatory, which is in a fine position overlooking the 
surrounding country. In recent years the growth of houses in the neighbourhood has been so rapid that its position will soon be spoilt, if it is not already.

The journey from Fremantle to Adelaide was livened by a lecture by Father Cortie on "Comets," and by Mr. McClean on "Flying." To give an idea of the low temperature conditions during this portion of the journey, furs and overcoats were generally worn, and my cabin temperature was about $65^{\circ} \mathrm{F}$. When at the Perth Observatory I was informed that the past season in Australia had been phenomenal, the summer having been cold and very wet. This I afterwards found was the case generally for the whole of the southern portion of the continent.

\section{Second Letter.}

April 1.

On the morning of March II we arrived at Adelaide, and moored alongside the quay. Father Cortie there received - letter from Captain Colomb, the captain of H.M.S. Encounter, the ship which had been put on special service to assist both Father Cortie and my party at the eclipse. Captain Colomb informed us that his ship was at present in dry dock at Coccatoo Island at Sydney, and that he

exceptional rainfall. At Bendifo we were shown over a battery of IIo stamps. The same evening we left for Melbourne, and the next morning Mr. Hunt, the Commonwealth meteorologist, took us to call on the Hon. King O'Malley, the Minister for Home Affairs. He very kindly welcomed us to Australia, and explained to us the working of his department. Mr. Hunt also showed us over the Meteorological Office of which he is chief. I was in time to see the very efficient system which he has adopted in making his daily forecasts for the whole of Australia. I made the acquaintance of Mr. G. H. Knibbs, the Commonwealth statistician. Next morning (March 15) I visited the Melbourne Observatory. Mr. Baracchi was there full of the question of the Boundary Commission and the coming eclipse, of which he is chief. I renewed my acquaintance with $\mathrm{Mr}$. Baldwin, who some years ago visited the Solar Physics Observatory at South Kensington, and also met Mr. Short, another assistant. I viewed with great interest the great Melbourne reflector, with which I was so familiar from book illustrations. My old friend Dr. Skeats, of the Royal College of Science, but now professor of geology at the Melbourne University, took me off to lunch to meet many of his confrères, and then we made a quick tour of the University. This University is growing very rapidly, and arrangements are already in preparation for a considerable increase of the various departments. I had the great pleasure of meeting Mr. Grayson there, who has so successfully achieved the art of ruling very thin lines on glass exceedingly close together-nearer together than those on any gratings yet ruled. He showed me the extremely ingenious methods he was adopting to produce the portions of the mechanism for ruling gratings. The work was of the very highest order, and he accomplishes every portion of it himself. It will be a grand day when we can order large-size ruled gratings from Australia.

On the morning of March I6 Mr. J. Brooks, retired Trigonometrical Survey of New South Wales, and Mr. W. E. Raymond, first assistant, Sydney Observatory, met us at the railway station. Both Mr. Brooks and $\mathrm{Mr}$. Raymond form part of my eclipse party, and both are

FıG. 2.-Rain Sqqualis on the Equator.

would be ready to sail with our party from Sydney on March 25 if that date was convenient. We informed him that this arrangement suited our plans admirably, and at his request we notified him of the amount of our luggage. At Adelaide Mr. Cooke, the Government astronomer of W. Australia, and Mr. Dodwell, the Government rronomer of S. Australia, met us. The Commonwealth Government placed a motor-car at our disposal, but unfortunately our time was so limited that we were unable to make much use of it.

The journey to Sydney proved most instructive. The region round Ballarat, where we visited my brother, is studded with past and present gold mines. There we were shown over the most up-to-date assaying plant, owned by Mr. Edwards. The following morning a motor run of roo miles brought us to Bendigo, and we had experience of Australian cross-country roads; in many cases it was a mere track, with no metal at all on it. I was told that I was seeing Australia under very abnormal conditions for that time of year, for instead of scenery of predominating brown tints, I was passing through a country as green as any scenery in England. This was due to the familiar with eclipse work, as they were with $\mathrm{Mr}$. McClean on his eclipse expeditions to Flint Island and Tasmania. Further, both Mr. McClean and I had been in correspondence with them from England, asking them to make many preparations locally, which they had most satisfactorily carried out. Our total instrumental and camp equipment was increased from $4 \frac{1}{2}$ tons to about 6 tons. I had intended to call on Vice-Admiral King Hall and Captain Colomb, of H.M.S. Encounter, as soon as possible, but found on my arrival that the former was away in Tasmania and the latter with his ship in dry dock. March I7 was a very busy day. First it was necessary to be down at the wharf to tally off all the eclipse cases as they came out of the Otway, though the majority were not going to be moved until late that evening. Then the Lord Mayor of Sydney was going to give us a civic welcome, which was to take place at noon that day. We all assembled at the Mansion House at the time appointed, and were met by Profs. Moors and Pollock, of Sydney University, the Rev. Father Pigot (representing the Eclipse Committee of the Australasian Society for the Advancement of Science), Mr. J. Mangle, the Rev. Dr

No. 2 I69, VOL. 86] 
Reseby, Dr. Quaife, Mr. Guthrie, Mr. W. E. Raymond, and Mr. Hamlet (representing the British Astronomical Association and the Royal Society).

Prof. Moors, introducing our two parties, remarked that the Australian expedition, which was going to Vavau to observe the eclipse, expected to learn a great deal from us. After Mr. Hamlet's reference to the voyage of Captain Cook in 1770, when he sailed to the South Seas to observe the transit of Venus, and also to the British and Commonwealth expeditions on the present occasion, the Lord Mayor heartily wished all the expeditions success, and instanced the voyages of Sir Ernest. Shackleton and Captain Percy Scott as showing what could be gained to science by close study under arduous conditions.

Prof. Pollock expressed the hope that the advent of the present British parties would benefit the scientific workers in Australia and raise and sustain that enthusiasm without which no good work was ever accomplished. Father Cortie replied in an appropriate manner, pointing out that Britishers felt quite at home in Australia, and that such expeditions helped to cement further, if necessary, the friendship between Australia and the Mother Country.

In my reply I laid particular stress on the importance of the occasion for furthering the proposal for a Solar Physics Observatory for Australia. I pointed out the importance of filling up the gap of longitude between Kodaikánal (India) and Mount Wilson Observatory (U.S.A.), and that in Australia the weather conditions were ideal for a large observatory of this kind. I also indicated the important part played by the sun in controlling our terrestrial atmospheric movements, and that a close study of the sun was of first importance to Austrafians, whose population was so largely composed of those who reaped benefit from the soil. After this pleasing ceremony was over we adjourned to another room to drink the health of the King.

In the afternoon we all went to Coccatoo Island to call on Captain Colomb, the ship being still in dry dock. He greeted us very heartily, and at his request we gave him an account of our programme and requirements.

In the evening we all attended a meeting of the British Astronomical Association, and at its conclusion $\mathrm{Mr}$. McClean, Mr. Anderson, and I went with Mr. Raymond to the observatory to see the show clusters, nebulæ, and double stars of the southern hemisphere.

The following morning was occupied in tallying all the eclipse cases from the Otway. These were to be transferred to H.M.S. Encounter by steam lighter on Monday, March 20. During the afternoon I boarded the Encounter to give Captain Colomb detailed information about the assistance required. I suggested to him the importance of communicating with England as soon as possible after the eclipse in order to inform the home authorities of our results. This he took in hand, and it was arranged that H.M.S. Encounter should send a wireless message to H.M.S. Pioneer at Auckland, which would be transmitted through to England by cable.

The next day (Sunday, March 19) we all went out by steamer to the beautiful River View Jesuit College, where Father Cortie and Brother. McKeon were staying. The rector and the fathers received us in a most hospitable manner. The college is situated away up towards the beautiful harbour of Port Jackson, and is an imposing structure amongst lovely scenery. Since our arrival in Sydney it had been very hot, and the damp atmosphere had made our various duties rather laborious; even the Australians considered it so. The steam to River View was delightful in the extreme, and we were able to gain some idea of the great future such an important port must have. There is very deep water everywhere, and the largest ships can lie alongside any of the innumerable harbours. At River View the very beautiful seismographs, which are in the charge of the distinguished worker Father Pigot, were shown to us. Every detail of these instruments and their functions were carefully pointed out.

The next day (March 20), at an early hour, the steam lighter was alongside the wharf, and $\mathrm{Mr}$. McClean and I went and superintended the placing of the cases in the lighter. Then we steamed away, and with the help of the Encounter's crew got all the cases safely stowed away in torpedo flats and other available spots.

NO. 2 I 69, vol. 86]
This morning I had expected Mr. Hunt to arrive from Melbourne, as I had been requested by the Hon. King O'Malley, the Minister for Home Affairs, through $\mathrm{Mr}$. Hunt, to visit and report on the proposed site for the Solar Physics Observatory near the new Federal Capital site, and Mr. Hunt was to escort me there and back. $\mathrm{Mr}$. Baracci had arranged to proceed to the site from Melbourne, and we were all to meet there. At midday I met Mr. Hunt, and he proposed that we should start the same evening, to which I consented. In the meantime, Mr. Hunt took me to call on Mr. Stephen Mills, the Collector of Customs, who is the successor to Colonel Lockyer (now retired); the latter I met in Melbourne a few days ago. Colonel Lockyer had very kindly given me two letters, one for Father Cortie, which would clear us of any difficulty that might arise in relation to custom duties. These proved very useful, and saved us much anxiety.

W. J. S. LOCKYER.

(To be continued.)

\section{THE WORK OF THE ROYAL GEOGRAPHICAL} SOCIETY.

$\mathrm{N}$ looking to the future, it is important to inquire how 1 the society will be able to maintain its reputation and its usefulness in the new conditions of geographical knowledge. It is true that the South Pole is as yet uncaptured, that the map of Arabia is still largely composed of great blank spaces, and that the bend of the Brahmaputra is drawn by guesswork in our atlases. But all these problems will, it is probable, be solved before long, and where then will be the field in which the explorer may hope to win renown by robbing the unknown of its romance? We must sooner or later face the fact that the work by which this society has become best known in the past represents an almost finished chapter in geographica history, and we should sometimes, in preparation for the future, ask ourselves what ought to be our rôle when the last leaf in that chapter has actually been turned.

When endeavouring thus to take time by the forelock, we should perhaps in the first place inquire more precisely as to the nature of the change which is now taking place and as to how soon it is likely to be accomplished. Systematic surveys are, we know, being pressed forward in many parts of the world, of which until recently the maps were produced mainly by the efforts of enthusiastic amateurs, whilst now they are turned out with almost machine-like regularity and precision by Government officials. As to the British Empire, the annual reports of the Colonial Survey Committee show how rapid has been the advance in this direction, and what satisfactory progress has been made, though in certain localities the authorities, in spite of past experience, seem disposed to linger on in a state of comparative topographical ignorance. Outside the British Empire similar changes are taking place, though less rapidly, with the result that when the international map of the world on the scale of I : $1,000,000$ is completed, as it will be before many years have passed, a large proportion of it will be hased on surveys sufficiently accurate to ensure the work holding good for many a century to come, except for the rise of new towns and the alteration in political boundaries. But in spite of all this progress there are likely to remain vast tracts of land, mapped in a fashion, no doubt, but with the details inaccurate and incomplete, where for at least half a century or more from this date the independent traveller will find ample opportunities of adding to the knowledge of the earth we live in. Indeed, for some years to come large areas are likely to exist our knowledge of which can only be increased at the risk of the traveller's life. But although the available topographical information concerning many regions will for long remain very imperfect, yet it is inevitable that the day will come when the whole world will be mapped with fair accuracy, and to that condition of things this society will have to adapt itself.

Nearly all great changes, however, take place gradually, the process of evolution being, as a rule, an advance

1 Extracts from tha address of the president, Mainr Leonard Darwin, at the anniversary meeting of the Royal Geographical Society, May 22. 